Ger J Exerc Sport Res 2021 · 51:269-276 https://doi.org/10.1007/s12662-021-00725-7 Received: 11 January 2021

Accepted: 13 May 2021

Published online: 28 June 2021

(c) The Author(s) 2021

\section{Introduction}

The concept of 'pedagogical content knowledge' (PCK) was introduced by Shulman (1986) as an answer to what he called a 'missing paradigm' in (research on) teaching and teacher education. By introducing PCK, Shulman wanted to emphasise the central role of subject matter and aimed at overcoming the artificial distinction between content and pedagogy. In recent decades, research on teaching and teacher education considers PCK to be a core component of professional competence (Blömeke, Gustafsson, \& Shavelson, 2015). There are different ways of thinking about PCK. Recent research on professional competencies of teachers is characterized by different theoretical approaches on the conceptualization and evaluation of teachers' professional competencies, namely dispositional versus behavioural approaches. Dispositional orientated approaches restrict the term competence to the sum of cognitive and motivational resources, assuming these multiple constituents are needed for competent performance. From this perspective, competencies are used to predict behaviour in criterion situations. Behavioural orientated approaches stress how cognition, affectmotivation and performance are linked together as a system (cobbled together in response to task demands) and change during the in-situation performance. From this point of view, competence is performance in real-world criterion situ-

\title{
Pedagogical content knowledge in students majoring in physical education vs. sport science. The same but different?
}

ations-observable behaviour (Blömeke, et al., 2015). Blömeke et al. (2015, p. 8) highlighted these two different ways of thinking about competence as "an unproductive dichotomy view of competence, in particular knowledge or performance, competence should be regarded as a process, a continuum with many steps in between". From a more integrated perspective it is of interest which processes connect both approaches (Krauss et al., 2020; for PE Baumgartner, 2018).

Beside this, special interest has been directed toward teachers' PCK since it predicts both the quality of teaching as well as student learning (e.g. Baumert et al., 2010; Iserbyt et al., 2020). PCK is of critical importance, "since it deals with teachers' knowledge necessary to achieve the aims of teaching" (Depaepe, Verschaffel, \& Kelchtermans, 2013, p. 15) by organising, representing, and adapting content to the diverse interests and abilities of learners and presented for instruction. Thus, PCK serves the function of providing the teacher with knowledge to transform the content in ways that make it understandable to learners.

This is of special importance to physical education (PE), since teaching $\mathrm{PE}$ is different from other school subjects in many significant ways. For example, PE takes place in unique learning environments (e.g., gym, swimming pool) and explicitly deals with students' body and corporeality. For example, performance is permanently staged through the bodies of the students (Alkemeyer, 2002). $\mathrm{PE}$ is the only compulsory school sub- ject through which children and young people can learn movement motor skills and acquire the knowledge to participate in a variety of physical activities. It is the only subject whereby physical activity is a primary means of accomplishing educational objectives-although with varying interpretations in different concepts across the European Union (EU) (MacPhail, Tannehill \& Avsar, 2019; Naul, 2003). It promotes the notion of learning in and through sports, physical activity, and exercise, targeting students' personal development as well as the development of sport-specific competences. PE aims at fundamental experience with one's own body and correlates this with reflection processes on one's own personal development, allows individual access to the body and thus to the world (Prohl, 2010). Hence, $\mathrm{PE}$ is critical to the education of the person in general and has the unique potential to promote integral human development. To date, research on PCK in the field of sport science has contained a "selection bias" (Depaepe et al., 2013, p. 22; Ward \& Ayvazo, 2016, p. 201) because different didactics foci in Europe and research traditions on subject matter didactics (Van Driel \& Berry, 2012) have received little interest. Especially in German speaking countries, research on PCK is still at the beginning (Vogler et al., 2018; Baumgartner, 2018; Heemsoth, 2016; Heemsoth \& Wibowo, 2020; Vogler, Messmer, \& Allemann, 2017; Wibowo \& Heemsoth, 2019). From a conceptual perspective, German 
scholars mostly refer to dispositional orientated and/or situated approaches (Vogler et al., 2018), whereas understandings of PCK "have been largely behavioural" in English-speaking publications (Backman \& Barker, 2020, p. 2). Since PCK is important in the sense of student learning, it is of particular interest to explore the extent to which PCK is a specific professional feature, thus providing insights into the conditions of PCK within various education programmes in sport science.

The highly specialised PCK is considered to be one of the main features distinguishing teachers from laypeople (Bromme, 2008; Mieg, 2001) and thus characterising their professional identity in a subject, also known as "professional knowledge hypothesis" (Baumert \& Kunter, 2006; Krauss, Baumert, \& Blum, 2008). For instance, PE teachers are professionals in at least two fields: they are both professionals in the field of sport science and professional teachers, whereas sport science students not aiming for a teaching degree are solely professionals in the field of sport science. The latter are related professionals since they are subject matter specialists. However, to the best of our knowledge, in the field of sport science, there is no study investigating whether students aiming for a teaching degree or not differ in their PCK. With regard to the noticing, a construct close to PCK, Reuker (2017) investigated differences in the noticing between groups with different expertise (i.e., athletes versus teachers). The findings indicate a connection between pedagogical expertise and a focus on teaching aspects. PE teachers with exclusively high levels of pedagogical expertise more frequently mentioned methodological and didactic approaches compared to athletes with exclusively high levels of sport-specific expertise (Reuker, 2017, 2018). Hence, one could assume differences in the PCK between subject matter specialists and teachers. In other domains scholars have reported higher PCK scores from teachers (Jüttner \& Neuhaus, 2013; Schmelzing et al., 2012). However, a comparison of student teachers and students majoring in mathematics showed that the student teachers' advantage in PCK can be attributed primarily to the "instruction" dimension (Krauss et al., 2008).

In addition, scholars have described that PCK is impacted by their own experiences with specific content together with the values and emotional connections derived from the content, which is pertinent to both Physical Education Teacher Education (PETE) and sport science students. Especially in the field of PE teaching, the professional identity is shaped by direct (personal) experiences with the activity. Pike and Fletcher (2014) stated that these experiences serve as foundation to view teaching and coaching as significantly different or not. For the United States, they concluded that there "are still many recruits who do come to physical education with the aim of becoming coaches" (Pike \& Fletcher, 2014, p. 12), even though teaching orientations are more prevalent prior to 2000. With respect to Germany there is evidence that many (future) PE teachers have taken up different roles in the field of physical activity (as athlete or coach) before their study (Meier 2015). Such experiences shape their view of teaching in a way that many (future) PE teachers tend to coaching orientations (Ernst, 2017; Klinge, 2019). A coaching orientation is focused more on skill mastery and less on the relation of content and pedagogy. Volkmann (2018) argued that experiences and values inform such orientations and can "block" the process of professionalization. This subject-specific phenomenon is stressed as a "unique and understudied area" in the context of PCK (Ward \& Ayvazo, 2016, p. 200).

Furthermore, scholars have shown that teacher education and professional development programmes provide opportunities to acquire PCK by attending workshops and lectures, collaborating with peers, and in teaching practice (Richter, 2013). As a result, preservice and beginner teachers adhered more to their written plan, while experienced teachers were able to depart from their plan to provide PCK in accordance with their students' abilities (Ward \& Ayvazo, 2016). Such learning opportunities during teacher education have fostered PCK and in turn students' learning (Iserbyt,
Ward, \& Martens, 2016; Iserbyt et al., 2020; Kim et al., 2018). A recent validation study in Germany showed that the PETE students' semester predicted PCK, whereas the grade point average did not. The authors conclude that this finding supports the qualification hypothesis (Heemsoth \& Wibowo, 2020).

Against this backdrop, the purpose of the current study is to compare the PCK of students studying different degree programmes in the field of sport science (PETE and sport science) in Germany. Despite the importance of PCK, no investigation has ostensibly been made into this issue to date. Although the number of studies measuring PCK is rising (Meier 2020; Heemsoth \& Wibowo, 2020; Vogler et al., 2017), no scale has been tested for measurement invariance across these two groups or additional variables relevant to PCK (i.e., prior experience in the field of physical activity). Measurement invariance is the precondition for comparing the PCK of such different groups, as PCK develops through different educational programmes and other non-formal learning opportunities. A meaningful and valid comparison of the PCK of both groups can be made only if a scale measures the same construct in both groups in the same way (Chen, 2008). Hence, the aims of the current study are as follows:

- The first purpose of the current study is to examine whether it is possible to measure PCK equivalently across PETE and sport science students, along with additional variables relevant to PCK (i.e., prior experience in physical activity, semester).

- With regard to the professional knowledge hypothesis, we compare latent mean scores of PCK in PETE and sport science students hypothesising that PETE students score higher on PCK than students from sport science. In addition, we explore the extent to which PCK differs across groups with prior experiences in physical activity.

- Based on evidence that the PETE students' semester predicted PCK, we hypothesise that PETE students score higher on PCK than sport science students in different stages of the study (semester). 


\section{Materials and methods}

\section{Participants}

Data were derived from the study "Higher, faster, stronger? Pedagogical content knowledge of sports teachers: conceptualization, measurement, validation". As shown in - Table 1, the global number of participants was 622 students in two different sport science degree programmes aged between 18 and 37. All participants were recruited from three public universities in one federal state of Germany, North-Rhine Westphalia. Most of the students were in their 2nd year of study and had prior experience in teaching in the field of sports ("In the last two years, how often did you coach/instruct/guide kids and/or youth in sports"). The sample comprises more males compared to females. One part of the sample comprised 431 PETE students aiming to become a teacher for upper secondary schools, the equivalent to International Standard Classification of Education (ISCED) 3. In Germany, teacher candidates decide at the very beginning of their study in which type of school they want to work after their graduation (within the PETE sample by entrance of studying). The other part of the sample comprised 191 sport science students aiming to graduate in the field of "Sport, Performance and/or Exercise".

\section{Study design}

The cross-sectional study investigated the PCK across PETE and sport science students. The research was conducted in classes during regular courses in the university. After receiving approval from the programme directors, paper-and-pencil tests were brought to the courses by two trained members of the project group. Surveys were conducted by trained test administrators as power tests without time limits. Participation was on a voluntary basis. The questionnaire itself included a covering letter with information about the purpose of the study, the benefits of participating in the study, and ethical issues related to anonymity and voluntariness. After the survey, participants could ask questions about the study in more detail. No incentives or compensation were offered for taking part in the survey. Data collection included standard sociodemographic information, e.g., age, gender.

\section{Measurements}

The 15-item "PCK-PE" (Meier 2020) was used to measure the PCK of PETE and sport science students. It includes two conceptually different PCK subscales: (1) knowledge of instructional strategies and (2) knowledge of students' (mis)conceptions and difficulties. The first "instruction" dimension highlights different representations and explanations of making the content comprehensible to others. The second "students" dimension assessed the ability to recognise students' conceptions and preconceptions about PE. The itemset consists of a mixture of open ended (example item PCK-PE "students" dimension: Imagine you teach swimming. From the student's perspective, which obstacles could be related to that? Name and describe two of them.) and multiplechoice questions (example item PCK-PE "instruction" dimension: In PE lessons, the student's body can be addressed relating to which kind of aspects? "The body as perception organ.” Please mark the box: right or wrong or I don't know). Responses are scored right or wrong. All items were coded independently by two trained raters using a standardised manual. A higher score indicated a more comprehensive PCK. Factorial and discriminant validity and good internal consistency for the subscales of the PCK-PE has been reported in a validation study (Meier 2020). In this study, the latent correlations between both PCK dimensions as computed on the basis of a configural invariance confirmatory factor analyses (CFA) model were 0.335 (PETE students) and 0.474 (sport science students). Discrimination between the two constructs of PCK was highest in group of the PETE students.

\section{Data analysis}

The data processing and frequency analyses were conducted using SPSS 26. Cor-
Ger J Exerc Sport Res 2021 · 51:269-276 https://doi.org/10.1007/s12662-021-00725-7 (c) The Author(s) 2021

\section{S. Meier \\ Pedagogical content knowledge in students majoring in physical education vs. sport science. The same but different?}

\section{Abstract}

Pedagogical content knowledge (PCK) is a special feature providing the teacher with knowledge to transform the content in ways that make it understandable to learners. This is of special importance in physical education (PE), since it is significantly different to other school subjects in many ways i.e., it is the only subject whereby physical activity (PA) is a primary means of accomplishing educational objectives. Given the importance of PCK, it is of special interest to explore the specificity of PCK in in the field of sport science. As research on PCK in German speaking countries is still at the beginning, a cross-sectional study was conducted among 622 students to explore potential differences in relation to education programmes (PE Teacher Education $n=431$, sport science $n=191$ ). Measurement invariance (MI) between the groups was carried out using multigroup confirmatory factor analysis models to ensure latent mean scores can be compared meaningfully. The progressive evaluation of $\mathrm{MI}$ confirms that it is possible to measure the PCK (scalar) equivalently across PETE and sport science students, along with additional variables relevant to PCK. PETE students outperformed sport science students in terms of the "instruction" subdimension (also in different stages of study), whereas not in the "student" subdimension. Prior experience in the field of PA is an advantage for high scores only in the "instruction" subdimension. Finally, the study provides first insights into the specificity of PCK in the field of sport science.

Keywords

Measurement invariance $\cdot$ Preservice physical education teachers - Professional knowledge · Sport science students · Subject matter

relation and multivariate analyses were calculated with Mplus 8.3 (Muthén \& Muthén, 1998-2012).

The first research question addresses the comparison of latent means between the two different study programmes 


\begin{tabular}{|c|c|c|c|c|}
\hline & & $M$ & $N^{a}$ & $\%$ \\
\hline Age (SD) & - & $21.96(2.61)$ & 617 & - \\
\hline \multirow[t]{3}{*}{ Semester (SD) } & - & $3.72(2.39)$ & - & - \\
\hline & Beginner & - & 314 & 51.06 \\
\hline & Advanced & - & 301 & 48.94 \\
\hline \multirow[t]{3}{*}{ Gender } & - & - & - & - \\
\hline & Female & - & 244 & 39.22 \\
\hline & Male & - & 378 & 66.77 \\
\hline \multirow{3}{*}{$\begin{array}{l}\text { Study Pro- } \\
\text { gramme }\end{array}$} & - & - & - & - \\
\hline & PETE (ISCED 3) & - & 431 & 69.29 \\
\hline & Sport Science & - & 191 & 30.71 \\
\hline \multirow{4}{*}{$\begin{array}{l}\text { Prior Experi- } \\
\text { ence }\end{array}$} & - & - & - & - \\
\hline & Often (> $3 \mathrm{~h} /$ week) & - & 170 & 27.38 \\
\hline & Sometimes (1-2 h/week) & - & 247 & 39.77 \\
\hline & Never & - & 204 & 32.85 \\
\hline
\end{tabular}

(PETE and sport science) preparing for different professions in the field of sport science. For this purpose, we investigated whether the testing instrument measured the constructs in the same way across groups, i.e., that the underlying constructs were invariant (equivalent) across different groups (Chen, 2008; van de Schoot, Schmidt, De Beuckelaer, Lek, \& Zondervan-Zwijnenburg, 2015). First, based on pre-existing findings the two-factor structure model of the "PCKPE" was tested through CFA including a review of modification indices. We then conducted a CFA to compare the fit of this two-factor model with the G-factor model to figure out the most parsimonious model for the following measurement invariance (MI) analyses. Following that, several nested models of multigroup CFAs (MGCFA) were conducted to study MI within the framework of structural equation modelling to determine the extent to which the factor structure was comparable across the study programme, stages of the study (semester), and prior experience in the field of physical activity. This approach involves setting cross-group constraints on parameters and comparing more restricted models with less restricted models (Millsap, 2011). Three steps were considered for the MI of categorically ordered data (Muthén \& Muthén, 1998-2012): the baseline model tested the original two-factor structure through a CFA for each group separately. Proceeding to the simultaneous MGCFA, the configural model and the scalar model were tested, from least restrictive to most restrictive. More restricted models were compared with less restricted models (nested models). Strong measurement invariance (scalar equivalence) across groups is a precondition for comparing means.

Given the categorically ordered data, the means and variance adjusted weighted least squares estimator (WLSMV) was chosen for all analyses (Flora \& Curran, 2004). The Mplus DIFFTEST option was used to conduct $\chi^{2}$ difference tests for the nested model comparison evaluation. As chi-square tests $\left(\chi^{2}\right)$ are sensitive to sample size and may reject models with even trivial misfit (Chen, 2007), we used the root mean square error of approximation (RMSEA, cut-off value for a good model fit $<0.06$, acceptable fit $<0.08$ ) and the comparative fit index (CFI, cutoff value for a good fit was $>0.95$ and acceptable fit $>0.90)$ to evaluate goodness of fit (Hu \& Bentler, 1999; Marsh, Hau, \& Wen, 2004). Chi-square difference tests between the nested models were applied in which the difference in $\chi^{2}$ value $\left(\Delta \chi^{2}\right)$ relative to the change in degrees of freedom $(\Delta \mathrm{df})$ was evaluated, as were changes in RMSEA ( $\triangle$ RMSEA) and CFI ( $\triangle \mathrm{CFI})$. Model equivalence was indicated by either a nonsignificant $\Delta \chi^{2}$ or $\Delta \mathrm{CFI}$ values $\leq 0.010$ and $\triangle \mathrm{RMSEA}$ values $\leq 0.015$ (Chen, 2007; Cheung \& Rensvold, 2002; Rutkowski \& Svetina, 2017).

To address the second and third research question, we examined differences in latent means across the study programme, stages of the study, and prior experience in the field of physical activity as these have been reported as significant to PCK (Heemsoth \& Wibowo, 2020; Iserbyt et al., 2020; Pike \& Fletcher, 2014; Ward \& Ayvazo, 2016). Effect sizes are not directly computed in Mplus, so to examine the magnitude of differences in latent means, we calculated an effect size $d$ for these differences. Common standards for small, medium, and large standardized effects are $0.2,0.5$, and 0.8 , respectively (Cohen, 1988).

\section{Results}

\section{Factor structure of the PCK-PE}

Based on prior findings, we hypothesised that a two-factor model would be an appropriate fit with the data (Meier, 2020), differentiating the two latent variables pedagogical content knowledge of instructional strategies (1) and pedagogical content knowledge of students' (mis)conceptions and difficulties (2). The CFA of this initial twofactor model resulted in an acceptable model fit: $\chi^{2}(d f)=305.157(89)$, $p<0.001, \mathrm{CFI}=0.980, \mathrm{RMSEA}=0.062$. To find a (more) parsimonious and wellfitting model, we reviewed modification indices. Although there were a few additional modifications, we did not make additional changes since it did not result in significant changes in fit indices. The G-factor model CFA was subsequently carried out on the basis of the initial two-factor model and resulted in a worse fit to the data, with all indices being worse compared to the initial model. The $\Delta \chi^{2}$ result indicated that the initial two-factor model fitted the data significantly better than the G-factor model $\left(\Delta \chi^{2}(\Delta d f)=42.063(1)\right.$, $p<0.001)$. These results indicated that the best model for the full sample was the modified two-factor model. Before the MI analysis, the initial two-factor model was tested on different study 


\begin{tabular}{|c|c|c|c|c|c|c|c|c|c|}
\hline Model & $x^{2}$ & $D f$ & $p$ & RMSEA & CFI & $\triangle R M S E A$ & $\triangle C F I$ & $\Delta x^{2}(\Delta d f)$ & $p$ \\
\hline \multicolumn{10}{|l|}{ Study Programme } \\
\hline $\operatorname{PETE}(n=431)$ & 222.544 & 89 & 0.000 & 0.059 & 0.981 & - & - & - & - \\
\hline Sport Science $(n=191)$ & 153.954 & 89 & 0.000 & 0.062 & 0.984 & - & - & - & - \\
\hline Configural & 373.575 & 178 & 0.000 & 0.059 & 0.982 & - & - & - & - \\
\hline Scalar & 390.058 & 189 & 0.000 & 0.058 & 0.981 & 0.001 & 0.001 & $21.450(11)$ & 0.029 \\
\hline \multicolumn{10}{|l|}{ Stage of the study ${ }^{a}$} \\
\hline Beginner $(n=314)$ & 165.399 & 76 & 0.000 & 0.054 & 0.986 & - & - & - & - \\
\hline Advanced $(n=301)$ & 145.274 & 76 & 0.000 & 0.049 & 0.986 & - & - & - & - \\
\hline Configural & 359.831 & 178 & 0.000 & 0.058 & 0.983 & - & - & - & - \\
\hline Scalar & 370.102 & 189 & 0.000 & 0.056 & 0.983 & 0.002 & 0.000 & $14.508(11)$ & 0.206 \\
\hline \multicolumn{10}{|l|}{ Prior experience ${ }^{b}$} \\
\hline Often $(n=170)$ & 162.782 & 89 & 0.000 & 0.070 & 0.978 & - & - & - & - \\
\hline Sometimes $(n=247)$ & 145.348 & 89 & 0.000 & 0.051 & 0.990 & - & - & - & - \\
\hline Never $(n=204)$ & 147.183 & 89 & 0.000 & 0.057 & 0.975 & - & - & - & - \\
\hline Configural & 456.482 & 267 & 0.000 & 0.059 & 0.983 & - & - & - & - \\
\hline Scalar & 469.721 & 298 & 0.000 & 0.055 & 0.984 & 0.004 & 0.001 & $19.520(22)$ & 0.613 \\
\hline \multicolumn{10}{|c|}{$\begin{array}{l}\Delta x^{2} \text { test is conducted using the DIFFTEST option for nested models } \\
\text { a } 7 \text { missing values } \\
\text { b } 1 \text { missing value }\end{array}$} \\
\hline
\end{tabular}

programme, stages of study, prior experience in the field of physical activity, and gender. Indices revealed that the twofactor model generally fits the data well in each subsample. Thus, the two-factor model can serve as the initial model for the subsequent MI tests.

\section{Measurement invariance across students}

- Table 2 contains the fit indices for the basic model in subsamples and each MI test step. Since there were two indicators loading on two factors, only the configural invariance model and scalar invariance model were tested in each group (i.e., study programme, stages of the study, and prior experience in the field of physical activity). First, we investigated MI across study programme, in which students were classed into a PETE group and a sport science group. This distinction reflects different paths of education in the context of sport science. Results of the configural and scalar invariance model indicated that the two-factor structure was verified across study programme. Both models fitted the data well. Though the $\chi^{2}$ difference test showed a significant $\chi^{2}(\mathrm{df})$ change, the changes in CFI and RMSEA values from the invariance configural model showed that the constrained model was not rejected. According to the "qualification hypothesis" (e.g., Heemsoth \& Wibowo; Iserbyt et al., 2020), we investigated whether stages of study affected the measurement model. Based on the year of study (selfreported), students were split into a beginner (1st year students) and a more advanced group (2nd year students and older). The configural and scalar invariance models both fitted the data equally well $\left(\Delta \chi^{2}(\Delta \mathrm{df})=14.508(11), p=0.206\right.$, $\Delta \mathrm{CFI}=0.000, \Delta \mathrm{RMSEA}=0.002)$. To examine the invariance between different prior experience in the field of physical activity, students were classed into three groups depending on their amount of experience: often (more than $3 \mathrm{~h}$ a week), sometimes (1-2h a week), and never. The $\chi^{2}$ difference test suggested that there is no significant deterioration in the model fit between the configural and scalar invariance model. In addition, the increase in CFI and RMSEA indicated an equal fit. Since all MI tests provided evidence for configural and scalar invariance of the two-factor PCK model in the PE(TE) students group and subsamples, comparisons of latent group-mean PCK scores seemed to be acceptable.

\section{Investigation of latent mean differences in PCK}

The differences between groups in the latent means for the two constructs of the PCK-PE are shown in - Table 3. Students scored significantly higher on the "instruction dimension" if they reported some prior experience in the field of physical activity (mean 0.479 higher) as well as more comprehensive experience (mean 0.977 higher) compared to those reporting no prior experience. The effect size for the difference in some experience was small $(d=0.240)$, but for the difference in comprehensive experience it was modest $(d=0.367)$. No differences appeared in the "students dimensions" at all. In terms of the study programme, PETE students' mean score was 0.627 higher compared to the sport science students in the "instruction dimension" only $(d=0.139)$, whereas there were no significant differences in the "students dimension". By comparing the means in both the study programmes in different stages of their study separately, PETE students scored higher on the "instruction dimension" than sport science-students at the beginning (mean 0.713 higher) as well as at the end of studying (mean 0.720 higher). The effect size for the difference at the beginning 


\begin{tabular}{|c|c|c|c|c|c|c|}
\hline & \multicolumn{3}{|c|}{ PCK-PE Instruction } & \multicolumn{3}{|c|}{ PCK-PE Students } \\
\hline & $M$ & SE & $p$ & $M$ & SE & $p$ \\
\hline \multicolumn{7}{|l|}{ Prior experience $^{a}$} \\
\hline Never $(n=204)$ & 0.000 & 0.000 & - & 0.000 & 0.000 & - \\
\hline Sometimes $(n=247)$ & 0.479 & 0.168 & 0.004 & 0.238 & 0.164 & 0.147 \\
\hline Often $(n=170)$ & 0.977 & 0.251 & 0.000 & 0.275 & 0.158 & 0.083 \\
\hline \multicolumn{7}{|l|}{ Study Programme } \\
\hline Sport Science $(n=191)$ & 0.000 & 0.000 & - & 0.000 & 0.000 & - \\
\hline $\operatorname{PETE}(n=431)$ & 0.627 & 0.122 & 0.000 & 0.206 & 0.129 & 0.109 \\
\hline \multicolumn{7}{|c|}{ Stage of the study/Study Programme ${ }^{b}$} \\
\hline \multicolumn{7}{|c|}{ Beginner/Study Programme $(n=314)$} \\
\hline Sport Science $(n=111)$ & 0.000 & 0.000 & - & 0.000 & 0.000 & - \\
\hline $\operatorname{PETE}(n=203)$ & 0.713 & 0.174 & 0.000 & 0.336 & 0.196 & 0.086 \\
\hline \multicolumn{7}{|c|}{ Advanced/Study Programme $(n=301)$} \\
\hline Sport Science $(n=76)$ & 0.000 & 0.000 & - & 0.000 & 0.000 & - \\
\hline $\operatorname{PETE}(n=225)$ & 0.720 & 0.216 & 0.001 & -0.009 & 0.163 & 0.954 \\
\hline
\end{tabular}

was small $(d=0.214)$ and at the end of studying it was even smaller $(d=0.028)$. There were no differences in the "students dimension", neither at the beginning nor at the end of studying.

\section{Discussion}

The objective of the current study was the PCK across PETE and sport science students in Germany. As research on PCK in German-speaking countries is still at the beginning, the current study contributes to a more comprehensive picture of the PCK, accounting for different didactics foci and research traditions on subject matter didactics in the EU. The aim was to discover the extent to which PCK is specific in the field of sport science.

In the first research question of this study, the factor structure of the PCKPE was examined across PETE and sport science students, along with additional variables relevant to the PCK (i.e., prior experience in the field of physical activity, stage of the study) via CFA and fitted the data acceptably. With the MGCFA procedure, we ensured that the factor structure was invariant across groups. Testing MI across groups is fundamental in making a reliable comparison of the PCK-PE scores between PETE and sport science students to obtain a valid statistical inference. The MI analysis indicated that the conceptual framework to define the two latent factors is equivalent for PETE and sport science-students in different stages of the study (semester), with different prior experience in the field of physical activity. In other words, it makes sense to compare the mean scores between PETE and sport science students in these different conditions (Chen, 2008; Cheung \& Rensvold, 2002). This is important as, to the best of our knowledge, there is no evidence in the field of sport science towards MI across such groups. In mathematics, Kleickmann et al. (2013) measured PCK with some variation between groups (i.e., scalar model). However, further evaluation of this variation did not specifically disadvantage any of the groups, which is in line with the findings of the current study.

With the second research question, the subsequent latent mean comparisons between PETE and sport science students provide further insights into the professional knowledge hypothesis. As hypothesised, the PCK of PETE students is specific to some extent. PETE students outperform the sport science students in terms of the "instruction dimension". This finding is consistent with findings in other domains (Jüttner \& Neuhaus, 2013; Schmelzing et al., 2012) supporting the assumption that pedagogical content knowledge of instructional strategies is a specific feature of PETE students. They are both professional sport scientists and professional teachers, whereas sport science students are rather professional sport scientists. Hence, knowledge in the "instruction dimension" distinguishes PETE students from sport science students. However, the effect size of the difference was small, and thus future research should study whether this is specific to the field of sport science.

In contrast, PETE and sport science students scored equally on the pedagogical content knowledge of students' (mis)conceptions and difficulties, which is consistent with the study of Krauss et al. (2008). Thus, it remains unclear why PETE and sport science students did not score differently on the "students dimension". According to the professional knowledge hypothesis, one could expect that PETE students score higher on this dimension compared to sport science students. As Shulman $(1986,1987)$ initially stated, if a (future) teacher does not know the interests and abilities of the student, then the teacher will be unable to match instruction to their students (Behets \& Vergauwen, 2006). Thus, the data support the interpretation that the "instruction dimension" may be a core aspect of PCK, as it is the most lesson-related sub-facet, and both must be integrated for an interactive teaching decision. Hence, this finding sensitises us to a deeper understanding of the similarity between both groups in the "students" dimension, which could date back to learning opportunities in PETE and sport science: To which extent are they specific in the "students" dimension and, moreover, how are they integrated in teaching? However, future research should tackle this in more detail. In addition, the study focused on PCK in the sense of dispositional oriented approaches. Hence, it remains an open question, how PCK is related to performance. From a more integrative point of view future research should "trace the long route from teacher disposition to student learning" (Krauss et al., 2020, p. 312) to investigate how much PCK predicts student learning and the steps in between. 
Furthermore, the findings highlight that prior experience in the field of physical activity is primarily associated with higher scores only on the "instruction" dimension, indicating that such experience is an advantage. However, in terms of the "students dimension", it is not. One could therefore argue that prior experiences do not sensitise students' (mis)conceptions and difficulties. This could indicate that subject specific experiences serve as foundation for a teaching orientation (Pike \& Fletcher, 2014) with respect to the "instruction" and not to the "students dimension". Future research should focus on the relevance of subject specific experiences in more detail.

With regard to the third research question, mean comparison in different stages of the study highlighted that PETE students only scored higher than sport science students on the "instruction dimension" at the beginning as well as at the end of studying. As the effect sizes for the differences were small, the results provide little evidence that learning opportunities during PETE are conducive to the development of the highly specialised PCK (e.g., Heemsoth \& Wibowo, 2020; Iserbyt et al., 2020). Unexpectedly, no differences appeared in the "students dimension". This may indicate that learning opportunities during education do not foster development that much. However, this must be tackled in more detail in future studies.

\section{Conclusion}

This study measured the PCK across PETE and sport science students and examined differences in latent means in subsamples (i.e., prior experience in the field of physical activity, stages of the study). It has been demonstrated that the factor structure of the PCK was invariant across (sub)groups; thus latent mean scores can be compared meaningfully. In line with the professional knowledge hypothesis, PETE students outperformed the sport science students in terms of the "instruction dimension", which is also pertinent in different stages of the study. In addition, prior experience in the field of physical activity is also associated with higher scores on this subdimension. It is the other way around in the "students dimension": PETE and sport science students did not score significantly different, also with respect to stages of the study. Prior experience is not an advantage for high scores on this subdimension.

Some limitations need to be considered when interpreting the results of the present study. Firstly, participants in the study were all from one region in Germany, aiming for a specific degree in a PETE (i.e., ISCED 3) and sport science programme, therefore the results apply only to these study programmes and do not allow generalisations. Since PCK is assumed to be affected by different traditions in subject matter didactics, which vary across the EU, the results can be seen as a case study or starting point for cross-cultural studies. Secondly, the complex nature of cross-sectional design prevents us from drawing causal conclusions. Although we tested MI and considered covariates, we cannot rule out that other factors confound the group differences in PCK. Remarkably, the comparison of students in different stages of the study must be taken as a tendency. Future, preferably longitudinal studies with prospective investigation should investigate the extent to which PCK develops during educational programmes and control for covariates (e.g., learning opportunities). Nevertheless, an interesting pattern of similarities between PETE and sport science students (at the beginning and end of studying) emerged: Differences do not lay within the "students dimension". Future research should cast light on this PCK subdimension. However, it must be pointed out that it is still unclear to what degree the findings of the current study relate to observable teacher behaviour in class and/or students' achievement. Finally, from a methodological point of view, it must be mentioned that the evaluation of (MG)CFA models and MI with categorical indicators is a field not well studied. Although the number of studies is rising, recommendations for using fit measures and cut-off values are based on only a few simulation studies (Rutkowski \& Svetina, 2017).

\section{Corresponding address}

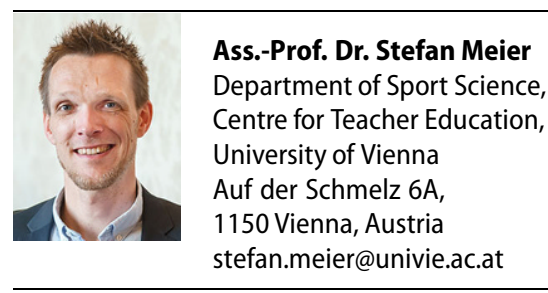

Funding. Open access funding provided by University of Vienna.

\section{Declarations}

Conflict of interest. S. Meier declares that he has no competing interests.

For this article no studies with human participants or animals were performed by the author. All studies performed were in accordance with the ethical standards indicated in each case.

Open Access. This article is licensed under a Creative Commons Attribution 4.0 International License, which permits use, sharing, adaptation, distribution and reproduction in any medium or format, as long as you give appropriate credit to the original author(s) and the source, provide a link to the Creative Commons licence, and indicate if changes were made. The images or other third party material in this article are included in the article's Creative Commons licence, unless indicated otherwise in a credit line to the material. If material is not included in the article's Creative Commons licence and your intended use is not permitted by statutory regulation or exceeds the permitted use, you will need to obtain permission directly from the copyright holder. To view a copy of this licence, visit http://creativecommons.org/licenses/by/4.0/.

\section{References}

Alkemeyer, T. (2002). Learning with the body and the possibilities of a practical reflexivity. European Journal of Sport Science, 2(1), 1-9. https://doi. org/10.1080/17461390200072106.

Backman, E., \& Barker, D.M. (2020). Re-thinking pedagogical content knowledge for physical education teachers - implications for physical education teacher education. Physical Education and Sport Pedagogy, 25(5), 451-463. https://doi. org/10.1080/17408989.2020.1734554.

Baumert, J., \& Kunter, M. (2006). Stichwort: Professionelle Kompetenz von Lehrkräften. Zeitschrift für Erziehungswissenschaft, 9(4), 469-520. https://doi.org/10.1007/s11618-006-0165-2.

Baumert, J., Kunter, M., Blum, W., Brunner, M., Voss, T., Jordan, A., Tsai, Y.-M., et al. (2010). Teachers' mathematical knowledge, cognitive activation in the classroom, and student progress. American Educational Research Journal, 47(1), 133-180. https://doi.org/10.3102/0002831209345157.

Baumgartner, M. (2018). „... Kompetenz ohne Performanz ist leer! Performanz ohne Kompetenz blind...!" Zu einem integrativen Kompetenzstrukturmodell von Sportlehrkräften. Zeitschrift für sportpädagogische Forschung, 6(1), 49-68.

Behets, D., \& Vergauwen, L. (2006). Learning to teach in the field. In D. Kirk, D. Macdonald \& 
M. O'Sullivan (Eds.), The handbook of physical education (pp. 502-515). London: SAGE. https:// doi.org/10.4135/9781848608009.n23.

Blömeke, S., Gustafsson, J. E., \& Shavelson, R. J. (2015). Beyond dichotomies: competence viewed as a continuum. Zeitschrift für Psychologie, 223(1), 3-13. https://doi.org/10.1027/2151-2604/ a000194.

Bromme, R. (2008). Lehrerexpertise. In W. Schneider \& M. Hasselhorn (Eds.), Handbuch der Pädagogischen Psychologie (pp. 159-167). Göttingen: Hogrefe.

Chen, F. F. (2007). Sensitivity of goodness of fit indexes to lack of measurement invariance. Structural Equation Modeling, 14(3), 464-504. https://doi. org/10.1177/0734282911406661.

Chen, F.F. (2008). What happens if we compare chopsticks with forks? The impact of making inappropriate comparisons in cross-cultural research. Journal of personality and social psychology, 95(5), 1005-1018. https://doi.org/ 10.1037/a0013193.

Cheung, G.W., \& Rensvold, R.B. (2002). Evaluating goodness-of-fit indexes for testing measurement invariance. Structural Equation Modeling, 9(2), 233-255. https://doi.org/10. 1207/S15328007SEM0902 5.

Cohen, J. (1988). Statistical power analysis for the behavioral sciences. Hillsdale: Erlbaum.

Depaepe, F., Verschaffel, L., \& Kelchtermans, G. (2013). Pedagogical content knowledge: a systematic review of the way in which the concept has pervaded mathematics educational research Teaching and Teacher Education, 34, 12-25. https://doi.org/10.1016/j.tate.2013.03.001.

Ernst, C. (2017). Professionalisierung, Bildung Fachkultur. Rekonstruktionen zur biographischen Entwicklung im Sportlehrerberuf. Wiesbaden: SpringerVS.

Flora, D. B., \& Curran, P.J. (2004). An empirical evaluation of alternative methods of estimation for confirmatory factor analysis with ordinal data. Psychological Methods, 9(4), 466-491. https://doi.org/10.1037/1082-989X.9.4.466.

Heemsoth, T. (2016). Fachspezifisches Wissen von Sportlehrkräften. Ein Überblick über fachübergreifende und fachfremde Ansätze und Perspektiven für die Professionsforschung von Sportlehrkräften. Zeitschrift für sportpädagogische Forschung, 4(2), 41-60.

Heemsoth, T., \& Wibowo, J. (2020). Fachdidaktisches Wissen von angehenden Sportlehrkräften messen. German Journal of Exercise and Sport Research, 50(2), 308-319. https://doi.org/10. 1007/s12662-020-00643-0

Hu, L., \& Bentler, P.M. (1999). Cutoff criteria for fit indexes in covariance structure analysis: conventional criteria versus new alternatives. Structural Equiation Modeling, 6(1), 1-55. https:// doi.org/10.1080/10705519909540118.

Iserbyt, P., Coolkens, R., Loockx, J., Vanluyten, K., Martens, J., \& Ward, P. (2020). Task adaptations as a function of content knowledge: a functional analysis. Research Quarterly for Exercise and Sport, 91(4), 539-550. https://doi.org/10.1080/ 02701367.2019.1687809.

Iserbyt, P., Ward, P., \& Martens, J. (2016). The influence of content knowledge on teaching and learning in traditional and sport education contexts: an exploratory study. Physical Education and Sport Pedagogy, 21(5), 539-556. https://doi.org/10. 1080/17408989.2015.1050662.

Jüttner, M., \& Neuhaus, B.J. (2013). Das Professionswissen von Biologielehrkräften. Ein
Vergleich zwischen Biologielehrkräften, Biologen und Pädagogen. Zeitschrift für Didaktik de Naturwissenschaften, 19,31-49.

Kim, I., Ward, P., Sinelnikov, O., Ko, B., Iserbyt, P., Li, W., \& Curtner-Smith, M. (2018). The influence of content knowledge on pedagogical content knowledge: an evidence-based practice for physical education. Journal of Teaching in Physical Education, 37(2), 133-143. https://doi. org/10.1123/jtpe.2017-0168.

Kleickmann, T., Richter, D., Kunter, M., Elsner, J., Besser, M., Krauss, S., \& Baumert, J. (2013). Teachers' content knowledge and pedagogical content knowledge. The role of structural differences in teacher education. Journal of Teacher Education, 64(1), 90-106. https://doi. org $/ 10.1177 / 0022487112460398$.

Klinge, A. (2019). Praktiken derSportlehrer*innenbildung zwischen De- und Professionalisierung. In J. Bietz, P. Böcker \& M. Pott-Klindworth (Eds.), Die Sache und die Bildung Bewegung, Spiel und Sport im bildungstheoretischen Horizont von Lehrerbildung, Schule und Unterricht (pp. 241-254). Baltmannsweiler: Hohengehren.

Krauss, S., Baumert, J., \& Blum, W. (2008). Secondary mathematics teachers' pedagogical content knowledge and content knowledge: validation of the COACTIV constructs. ZDM: the international journal on mathematics education, 40(5), 873-892. https://doi.org/10.1007/s11858-0080141-9.

Krauss, S., Bruckmaier, G., Lindl, A., Hilbert, S., Binder, K., Steib, N., \& Blum, W. (2020). Competence as a continuum in the COACTIV Study: the "Cascade Model". ZDM: The International Journal on Mathematics Education, 52(2), 311-327. https:// doi.org/10.1007/s11858-020-01151-z.

MacPhail, A., Tannehill, D., \& Avsar, Z. (Eds.). (2019). European physical education teacher education practices. Initial, induction, and professional development. Maidenhead: Meyer \& Meyer.

Marsh, H. W., Hau, K.-T., \& Wen, Z. (2004). In search of golden rules: comment on hypothesistesting approaches to setting cutoff values for fit indexes and dangers in overgeneralizing $\mathrm{Hu}$ and Bentler's (1999) findings. Structural Equation Modeling, 11(3), 320-341. https://doi.org/10. 1207/s15328007sem1103 2.

Meier, S. (2015). Kompetenzen von Lehrkräften. Eine empirische Studie zur Entwicklung fachübergreifender Kompetenzeinschätzungen. Münster: Waxmann.

Meier, S. (2020). Development and validation of a testing instrument to assess pedagogical content knowledge of German preservice physical education teachers. Journal of Physical Education and Sport, 20(5), 3010-3016. https:// doi.org/10.7752/jpes.2020.55409.

Mieg, H. (2001). The social psychology of expertise: case studies in research, professional domains, and expert roles. Hillsdale: Lawrence Erlbaum.

Millsap, R. E. (2011). Statistical approaches to measurement invariance. New York, NY: Routledge.

Muthén, L. K., \& Muthén, B. O. (1998-2012). Mplus user's guide. Los Angeles: Muthén \& Muthén.

Naul, R. (2003). Concepts of physical education in Europe. In K. Hardman (Ed.), Physical education: deconstruction and reconstruction, issues and directions (pp. 35-52). Schorndorf: Hofmann.

Pike, S., \& Fletcher, T. (2014). A review of research on physical education teacher socialization from 2000-2012. PHEnexJournal, 6(1), 1-17.

Prohl, R. (2010). Grundriss der Sportpädagogik. Wiebelsheim: Limpert.
Reuker, S. (2017). The noticing of physical education teachers: a comparison of groups with different expertise. Physical Education and Sport Pedagogy, 22(2), 150-170.

Reuker, S. (2018). „Ich unterrichte so, wie es die Ereignisse erfordern" - Der professionelle Blick von Sportlehrkräften und seine Bedeutung für adaptiven Unterricht. Zeitschrift für sportpädagogische Forschung, 6(2), 31-53.

Richter, D. (2013). Professional development across the teaching career. In M. Kunter, J. Baumert, W. Blum, U. Klusmann, S. Krauss \& M. Neubrand (Eds.), Cognitive activation in the mathematics classroom and professional competence of teachers Results from the COACTIV project (pp.333-342). New York: Springer.

Rutkowski, L., \& Svetina, D. (2017). Measurement invariance in international surveys: categorical indicators and fit measure performance. Applied Measurement in Education, 30(1),39-51. https:// doi.org/10.1080/08957347.2016.1243540.

Schmelzing, S., van Driel, J., Jüttner, M., Brandenbusch, S., Sandmann, A., \& Neuhaus, B.J. (2012). Development, evaluation, and validation of a paper-and-pencil test for measuring two components of biology teachers' pedagogical content knowledge concerning the 'cardiovascular system. International Journal of Science and Mathematics Education, 11, 1369-1390. https:// doi.org/10.1007/s10763-012-9384-6.

Shulman, L.S. (1986). Those who understand: knowledge growth in teaching. Educational Researcher, 15(2), 4-14. https://doi.org/10. 3102/0013189X015002004.

Shulman, L.S. (1987). Knowledge and teaching. Foundations of the new reform. Harvard educational review, 57(1), 1-22. https://doi.org/ 10.17763/haer.57.1.j463w79r56455411.

Van Driel, J.H., \& Berry, A. (2012). Teacher professional development focusing on pedagogical content knowledge. Educational Researcher, 41(1), 26-28. https://doi.org/10. 3102/0013189X11431010.

Van De Schoot, R., Schmidt, P., De Beuckelaer, A., Lek, K., \& Zondervan-Zwijnenburg, M. (2015). Editorial: measurement invariance. Frontiers in Psychology, 6, 1064. https://doi.org/10.3389/ fpsyg.2015.01064.

Vogler, J., Messmer, R., \& Allemann, D. (2017). Das fachdidaktische Wissen und Können von Sportlehrpersonen (PCK-Sport). German Journal of Exercise and Sport Research, 47(4), 335-347. https://doi.org/10.1007/s12662-017-0461-4.

Vogler, J., Messmer, R., Wibowo, J., Heemsoth, T., \& Meier, S. (2018). Drei Zugänge zur Modellierung fachdidaktischen Wissens von Sportlehrpersonen. In E. Balz \& D. Kuhlmann (Eds.), Sportwissenschaft in pädagogischem Interesse (pp. 47-55). Hamburg: Czwalina.

Volkmann, V. (2018). Sportbiographische Kontinuität als Blockade im Professionalisierungsprozess Eine fallrekonstruktive Betrachtung. In B. Fischer, S. Meier, A. Poweleit \& S. Ruin (Eds.), Empirische Schulsportforschung im Dialog (pp. 101-113). Berlin: Logos.

Ward, P., \& Ayvazo, S. (2016). Pedagogical content knowledge: conceptions and findings in physical education. Journal of Teaching in Physical Education, 35(3), 194-207. https://doi.org/10. 1123/jtpe.2016-0037.

Wibowo, J., \& Heemsoth, T. (2019). Zur Konzeption und Validität eines Tests zum fachdidaktischen Wissen von Sportlehrkräften. Zeitschrift für sportpädagogische Forschung, 7(2), 88-108. 